\title{
Toll-like Receptors as a Potential Drug Target for Diabetes Mellitus and Diabetes-associated Complications
}

This article was published in the following Dove Press journal: Diabetes, Metabolic Syndrome and Obesity: Targets and Therapy

\author{
Awgichew Shewasinad \\ Yehualashet (ID \\ Pharmacology and Toxicology Unit, \\ Department of Pharmacy, College of \\ Health Sciences, Debre Berhan \\ University, Debre Berhan, Ethiopia
}

Correspondence: Awgichew Shewasinad Yehualashet

Pharmacology and Toxicology Unit,

Department of Pharmacy, College of

Health Sciences, Debre Berhan

University, Debre Berhan, Ethiopia

Tel +251935450290

Email awgshewa@gmail.com

\begin{abstract}
Diabetes mellitus (DM) is a chronic endocrine disease distinguished by hyperglycemia due to disturbance in carbohydrate or lipid metabolism or insulin function. To date, diabetes, and its complications, is established as a global cause of morbidity and mortality. The intended aim during the management of diabetes is to maintain blood glucose close to normal because the majority of patients have poor control of their elevated blood glucose and are highly prone to severe macrovascular and microvascular complications. To decrease the burden of the disease and its complications, scientists from various disciplines are working intensively to identify novel and promising drug targets for diabetes and its complications. Increased and ongoing investigations on mechanisms relating to diabetes and associated complications could potentially consider inflammatory cascades as a promising component of the strategy in the prevention and control of diabetes and its complications. The potential of targeting mediators of inflammation like toll-like receptors (TLRs) are part of current investigation by the scientific community. Hence, the aim of the present review is to discuss the role of TLRs as a potential drug target for diabetes and diabetes associated complications.
\end{abstract}

Keywords: diabetes mellitus, TLR, immunity, inflammation, complication

\section{Introduction}

Diabetes mellitus (DM) is a chronic endocrine disease distinguished by hyperglycemia because of deregulations of carbohydrate or lipid metabolism or insulin function. The chronic hyperglycemic condition of the disease is correlated with relatively specific long-lasting microvascular and macrovascular complications. ${ }^{1,2}$ Based on etiology and clinical presentation of the disease, there are four types of DM; insulin dependent, noninsulin dependent, gestational, and other specific types of DM. ${ }^{3,4}$

Regulating the body's blood glucose is crucial as complications of the vascular system are the major causes of death in diabetic patients. Persistent hyperglycemia and diabetes induced microvascular (retinopathy, neuropathy, and nephropathy) and macrovascular (heart attack, stroke, and peripheral arterial disease) complications are the major characteristic features of all types of DM. Apart from hyperglycemia, it is also distinguished by elevated level of oxidative stress indices, eg lipid peroxidation, decreased level of antioxidant defenses and dyslipidemia. The integrity of the liver is compromised and this is reflected by disturbances in glucose metabolism and activities or levels of biomarkers of liver function. Oxidative stress in diabetic patients induce the development of macro and microvascular complications causing the incidence of atherosclerosis, kidney diseases, and neuropathy. ${ }^{5}$ 
Diabetic retinopathy (DR), among the microvascular complications affects the tiny retinal vessels; arterioles, capillaries and veins due to an increase in vascular permeability, ocular hemorrhages, lipid exudate, closure of the vasculature mediated by the formation of new vessels on the retina and posterior vitreous area. This common complication of DM is assumed to be the major rationale leading to problems in vision and potential blindness. ${ }^{6}$ Patients with diabetes and/or reduced kidney function are highly prone to diabetic kidney disease (diabetic nephropathy), which also might be caused as a consequence of hypertensive nephrosclerosis and unresolved acute kidney failure. ${ }^{7}$ Diabetic foot ulcer (DFU) is ulceration on the foot that is associated with a neuropathic condition and/or peripheral arterial disease affecting the lower limb in patients with diabetes. ${ }^{4}$ Neuropathy, ischemia, and infection are the most common classical set of causes of DFU. Dysfunction in the metabolic mechanisms in the case of DM increases the risk of infection and delays wound healing. The mechanisms of infection is probably due to series of activities involving reduced cell and growth factor response, reduced peripheral blood flow and diminished local angiogenesis which thereby results in damage to peripheral nerve and peripheral vascular disease. Therefore, ulcerations, deformities, and gangrene occur. ${ }^{8,9}$

The prevalence of DM and its complications are continually rising with the ageing population and lifestyle changes, which are direct consequences of rapid urbanization and westernization of countries. The disease covers every area of the globe and is rapidly rising. In 2017, globally, about 451 million individuals in the age group of 18-99 were living with diabetes and the number is expected to increase to 693 million by the year 2045, out of which $90 \%$ of them could have type 2 diabetes. ${ }^{10}$ The worldwide estimation of diabetes in adults (20-79 years) was about half a billion with a prevalence rate of $3.2 \%$ in Africa, approximately 0.8-3.5 million people in Ethiopia are living with the disease. ${ }^{11,12}$ A study on the epidemiology of complications of DM in Ireland reported the incidence of (6.5-25.2\%) retinopathy, (3.2-32.0\%) neuropathy and (2.5-5.2\%) nephropathy cases. ${ }^{12}$ Diabetic neuropathy in the eastern Africa; Sudan was about (31.5\%) in inpatient and (36.7\%) in the outpatient clinical scenarios. ${ }^{13}$ In Ethiopia, the abovementioned complications of diabetes are also estimated to be neuropathy (35\%), retinopathy (25\%), and nephropathy (15\%), diabetic foot ulcer (25\%), and impotency $(44 \%) .{ }^{14}$ In order to reduce this burden, conventional approaches including certain newer agents have been employed in the management strategy of DM.

The conventional approaches in the management of DM include lifestyle modification and dietary therapy, using oral antidiabetic agents and insulin therapy. Since prevention of onset and progression of its complications are considered as a prerequisitet in order to achieve the goal of diabetic treatment; diabetes treatment should imply more than simply reducing the blood glucose levels. $^{8,15}$ The older oral hypoglycemics are sulphonyl urea, alpha-glycosidase inhibitors and biguanides, whereas the newer agents include incretin based agents, kidney glucose reabsorption inhibitors (SGLT2 inhibitors), glucokinase activators, injectable and glucagonlike peptide (GLP) analogs and agonists. ${ }^{16}$ Although insulin and oral hypoglycemic drugs are the first line of treatment for DM, they have some undesirable effects and are unable to dramatically alter the course of diabetic complications. In addition, safety of most of the presently used drugs is not established during pregnancy. A daily intravenous administration and hypoglycemia during insulin therapy are also the most frequently noted unwanted effects. ${ }^{17,18}$ The majority of patients have poor control of the level of blood glucose and are highly prone to severe complications. Therefore, there is a huge need to develop novel therapeutic agents with reduced level in the development and progression of the disease and its complications. However, there are scientific advances in biomedicine development and target scrutiny, but the treatment of diabetes is still a big challenge. Hence, scientists from various disciplines are in intense research to identify novel and promising drug targets in the management of DM and its complications. Hence, the aim of the present review is to discuss the role of toll-like receptors (TLRs) as a potential drug target for diabetes and diabetes associated complications. TLRs are important immunity sensors or pattern recognition receptors (PRRs) for endogenous or exogenous ligands and they are involved in crucial cellular pathways through the activation of intracellular signaling molecules. The role of immunity and diabetes in connection with TLRs are discussed in the next sections.

\section{Diabetes Mellitus and Immunity} Immunity in Type I and Type 2 DM

The body's immune system is a responsible networking mechanism to safeguard the body from pathogens via 
cellular interactions and humoral factors using multiple specialized cell types such as cytokines. Innate immunity is the front line of defense that recognizes common components of pathogens to further provoke immune responses. The natural immune mechanisms are host defensive actions triggering an autoimmune response to antigens of the host's own tissue, in which the responses to these self antigens do not result in disease progression rather autoimmune disease occurs only when tissue damage occurs as a consequence of the continued autoimmune responses. ${ }^{19,20}$

The adaptive line of immune mechanism is an antigenspecific system that is responsible for producing immunological memory and $\mathrm{T}$ cell and antibody responses specific to pathogens or infected cells. This course of immunity can discriminate nonself molecules by recognizing peptide antigens using receptor interaction between $T$ cells and the antigen presenting cells (APCs). Responses due to long term immunological memory developed by the adaptive immunity, triggers the clonal expansion of $\mathrm{T}$ lymphocytes, to thereby communicate with $\mathrm{B}$ cells to induce production of antibodies specific to antigens. ${ }^{21}$ In contrast to the adaptive immunity, innate immunity recognizes foreign molecules or pathogens not by previous exposure to them; rather it is achieved by the use of pattern recognition molecules that can recognize the conserved molecular patterns found in foreign molecules, as well as several cell products that can attack the defenses of our body. The membrane bound pattern recognition molecules include TLRs. $^{21,22}$

Type $1 \mathrm{DM}$ is an autoimmune disease as a consequence of specific adaptive immunity against the $\beta$ cell antigens; however, the innate line of defense mechanism has a role in the establishment of specific $\beta$ and $\mathrm{T}$ cell immunity and its maintenance. ${ }^{23}$ Type $2 \mathrm{DM}$ is distinguished in abnormal elevation of blood glucose because of deregulation in insulin secretion, glucose intolerance, and hyperglycemia. Both innate and adaptive immunity are enumerated factors having an important etiological component for insulin resistance. $^{24,25}$

The abnormal innate and adaptive immunity are expressed as alterations in proliferation of $\mathrm{T}$ cells and macrophages, and impairment in function of NK cells and $\beta$ cells in patients with type $2 \mathrm{DM}$ and obesity or both. In type $2 \mathrm{DM}$, inflammatory cytokines having deleterious potential on the disease pathogenesis are produced inappropriately by the immune cells. Increment in the level serum inflammatory cytokines such as IL-6, IL-18 and TNF- $\alpha$ have been reported in type 2 diabetic patients and associated complications. In obese and diabetic cases, it is worth critically understanding that the implication of innate immunity and adaptive immunity thereby paves a way in revealing novel immunotherapeutic modalities to optimize metabolic inflammation and insulin resistance. ${ }^{24,25}$ Obesity is majorly observed in patients with type $2 \mathrm{DM}$ and the risk increases in line with a rise in BMI. Basically, obesity is not an entirely distinguished risk factor for autoimmunity rather glucose intolerance and emergence of insulin resistance are enumerated among others. The overlapping existence of being overweight and autoimmunity is probably due to consequence of dysregulatory mechanisms of immune tolerance that involves different organs. ${ }^{26,27} \mathrm{~B}$ lymphocytes are important in humoral immunity, which is part of the adaptive immune mechanism. In addition to selection of antibodies, they can present antigens and also secrete cytokines. Murine mouse models have shown B cell involvement in the emergence of insulin resistance. An obese null New Zealand mice knockout of $\mathrm{B}$ cells showed no insulin resistance in response to obesity. Likewise, another investigation showed that either with the use of drugs or by genetically knocking out of B cells is sufficient to dramatically suppress immune cell infiltration and inflammation in adipose tissue, finally enhancing sensitivity of insulin. ${ }^{28,29}$

The attempt in the treatment of diabetes is to prevent the loss of residual B cell function in type 1 diabetes for protection and/or regeneration. Immune modulation and autoantigen vaccination are the most commonly used approaches to restore immune tolerance. ${ }^{26,27}$ Type 1 diabetes is clearly an autoimmune disease and similarly an autoimmune reaction with a limited extent contributes to the pathogenesis of type 2 diabetes and antigen-specific therapies are still not in sight for the treatment of both types of diabetes. However, considering the prominent role of activation of innate immune system in adipose tissue inflammation and type 2 diabetes, anti-inflammatory and immune-modulatory therapeutic strategies may be viewed as relevant in regulating the metabolic process in type 2 diabetes. Targeting IL- $1 \beta$ and an inflammatory cytokine have shown promising results with central role in islet inflammation in type 2 diabetes. IL-1R antagonist, anakinra, reverses the effect of inflammatory cytokines and showed favorable results in improving glucose control in type 2 patients. $^{30}$

The innate immune mechanism uses pattern recognition receptors (PPRs) to detect microbes. PPRs are identified to recognize microbe specific molecular markers the so-called pathogen-associated molecular patterns (PAMPs) and self-molecules derived from damaged cells, known as 
damage associated molecular patterns (DAMPs). PRRs stimulate the downstream cascade to provoke innate immune responses so as to produce inflammatory cytokines; type I interferon (IFN) and other mediators. Hence, the process leads to an immediate host defensive mechanism including inflammation and initiates production of antigen-specific adaptive immune responses. TLRs are among PPRs to be targeted in regulating the human immune system and inflammatory cascades. ${ }^{31}$ This review tries to describe the relevant roles of TLRs in diabetes and associated complications.

\section{TLRs and Diabetes}

\section{Overview of TLRs}

TLRs are an important immunity sensors or PRRs for endogenous or exogenous ligands and they are involved in crucial cellular pathways through the activation of intracellular signaling molecules. About 10 different TLRs (TLR1-TLR 10) are found in humans, whereas 12 TLRs (TLR1- 9, TLR11-13) are found in mice. An individual TLR has an ectodomain with leucine-rich repeats (LRRs) which can mediate recognition of PAMPs, transmembrane domain, and a cytoplasmic toll/IL-1 receptor (TIR) domain that is responsible to initiate the downstream signaling pathway. The ectodomain has horse-like receptors that aids the interaction of TLRs with respective DAMPS/PAMPS/TLRs as a homo/heterodimer along with a coreceptor or other accessory molecules. ${ }^{31}$

\section{Signaling Pathways of TLRs}

TLRs can recognize specific ligands and elicit immune response after recognizing specific ligands such as PAMPs and DAMPs. Endogenous ligands like saturated fatty acids (SFA), modified low density lipoproteins (LDL), heat shock proteins (HSPs), high-mobility group box 1 ( $H M G B 1)$, extracellular matrix degradation products, and advanced glycation end products, are considered to be DAMPs which are recognized by TLRs (especially TLR 2/4). Ligand binding with TLRs can trigger a pro-inflammatory response. ${ }^{32}$ The activation of TLR stimulates the signalizing pathway as a defense mechanism towards invaders and restores the damaged tissues tending to release various inflammatory cytokines and immune modulators. TLR cascading encompasses at least two separate pathways as illustrated in (Figure 1), The myeloid differentiation factor 88 (MyD88) dependent pathway is employed by all

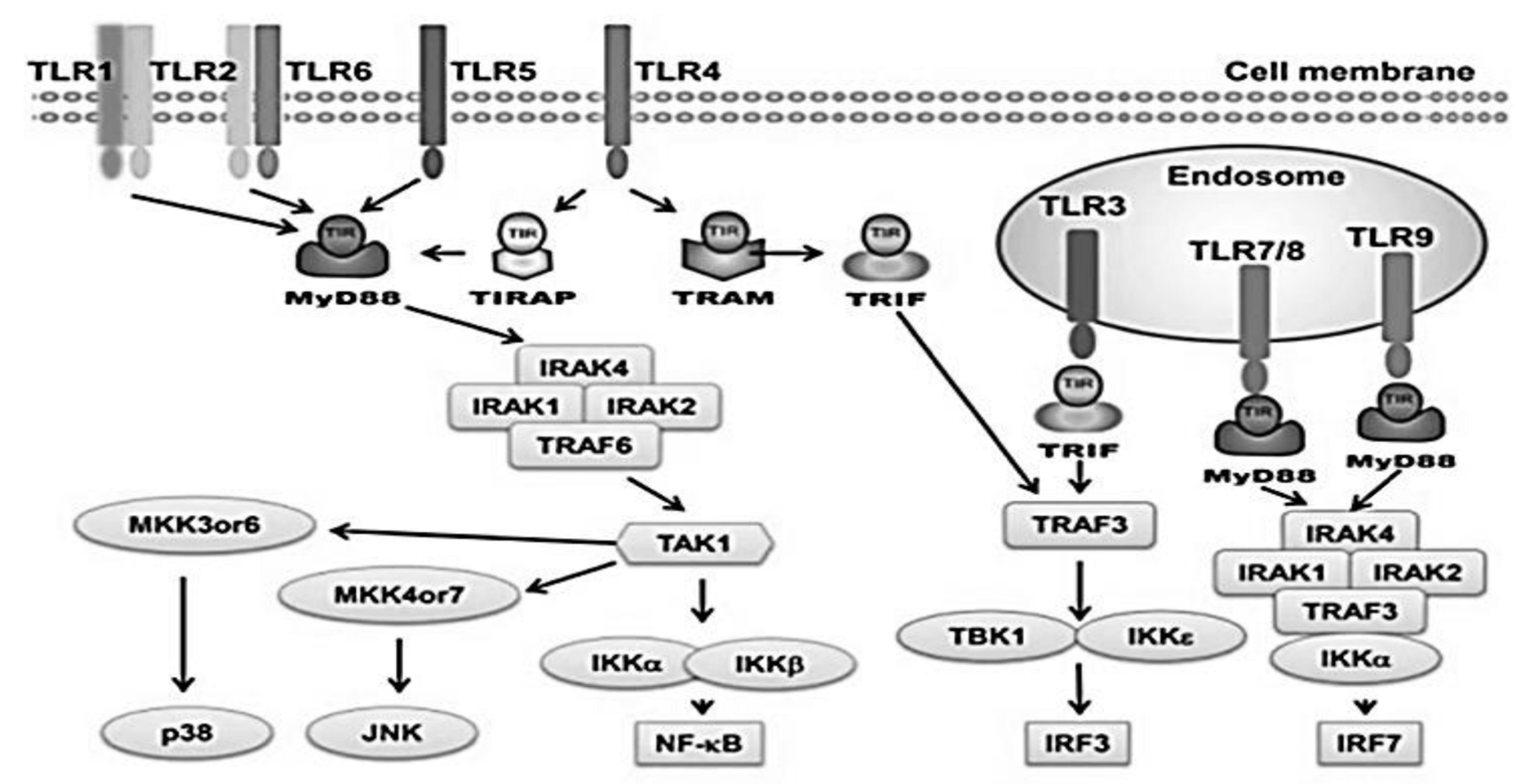

Pro-inflammatory cytokines

Type 1 IFN

Figure I TLR signalling pathway.

Notes: Reproduced from El- Zayat SR, Sibaji H, Manna FA. Toll like receptors activation, signaling and targeting: an overview. Bulletin of the national research centre.20I9;43 (187): I- $12 .{ }^{32}$ Creative Commons license and disclaimer available from: (http://creativecommons.org/licenses/by/4.0/legalcode). 
Table I Animal and Human Studies on Toll-like Receptors and Effects on Cardiovascular System

\begin{tabular}{|c|c|c|}
\hline Animal/Human Studies & Findings & Ref \\
\hline $\begin{array}{l}\text { ECs of aorta from LDLr-I-- mice were revealed to a disturbed } \\
\text { blood flow }\end{array}$ & $\begin{array}{l}\text { TLR } 2 \text { expression was observed in the early atherosclerosis } \\
\text { plaques. }\end{array}$ & 60 \\
\hline Hyperlipidemia due to large amount of fat ingestion in mice & $\begin{array}{l}\text { Enhances expression of TLR2, and TLR2 deficit reduces EC } \\
\text { dysfunction, intimal leukocyte and lipid accumulation. }\end{array}$ & 60 \\
\hline LDLr-I- mice model & $\begin{array}{l}\text { Deficiency in TLR2 results a half reduction in aortic atherosclerosis } \\
\text { revealing the immense significance of this receptor. }\end{array}$ & 61 \\
\hline TLR2 depletion in mice & $\begin{array}{l}\text { Precludes the generation of atherosclerosis when synthetic TLRI/2 } \\
\text { agonist is administered. }\end{array}$ & 61 \\
\hline $\begin{array}{l}\text { TLRI or TLR6 LDLr-/- mice model (TLR2 has linkage with TLRs I } \\
\text { and } 6 \text { in signal transmission, the model is used to identify the co- } \\
\text { receptor of TLR2 involved in TLR2 mediated atherosclerosis) }\end{array}$ & $\begin{array}{l}\text { Although, depleting (TLRs I and 6) showed no effect on } \\
\text { development of lesion without exogenous agonists, deficiency of } \\
\text { TLRs I and } 6 \text { reduce the progression of atherosclerosis with } \\
\text { exogenous TLRI and TLR6 ligands, respectively (probably due to } \\
\text { response of TLRs I and } 6 \text { for unidentified endogenous TLR2 } \\
\text { ligands). }\end{array}$ & 81 \\
\hline In Apo lipoprotein E-I- mice model & $\begin{array}{l}\text { Reduced TLR2 showed protection in the formation of aortic } \\
\text { atherosclerotic plaque, might be because of reduced lipid } \\
\text { aggregation and macrophage entry to aortic sinus in addition to } \\
\text { decreed monocyte chemoattractant protein-I (MCP-I) levels }\end{array}$ & 82 \\
\hline Hypercholesterolemia rabbit model & $\begin{array}{l}\text { In the aorta, it was observed that mRNA expression of TLR3 was } \\
\text { highly upregulated }\end{array}$ & 83 \\
\hline In mice (wild type) and intact TLR3 & $\begin{array}{l}\text { Function of ECs was impaired due to systemic administration of } \\
\text { TLR3 agonists }\end{array}$ & 84 \\
\hline In mice model with LDLr-I- & $\begin{array}{l}\text { TLR } 3 \text { deficit in hematopoietic cells produces protection from the } \\
\text { generation of atherosclerosis while the level of circulating lipids are } \\
\text { unchanged }\end{array}$ & 85 \\
\hline In Apo lipoprotein E-I- mice model & $\begin{array}{l}\text { TLR3 showed protection against arterial injury and atherogenesis } \\
\text { while depletion of the receptor enhances formation of atherosclerosis }\end{array}$ & 86 \\
\hline In mice with TLR3 deficiency & $\begin{array}{l}\text { It was observed that the amount of collagen and SMS was raised in } \\
\text { the lesion of atherosclerosis implying the contribution of TLR3 to } \\
\text { cause disturbance in the area of plaque due to partial controlling of } \\
\text { the function of MMP-2 and MMP-9 in macrophages. }\end{array}$ & 87 \\
\hline In human platelet & $\begin{array}{l}\text { It was showed that TLR3 in human platelet can promotes the } \\
\text { aggregation of platelet, release of ATP release, and stimulation of } \\
\text { integrin. }\end{array}$ & 88 \\
\hline In patient atherosclerotic plaques & $\begin{array}{l}\text { TLR4 (predominant expression in blood vessels), TLRs } 2 \text { and } 4 \\
\text { antibodies blocked the formation of thrombin mediate by histone } \\
\text { and pro-coagulant phenotype human platelets, implicating these } \\
\text { two receptors are involved in the process of blood coagulation. }\end{array}$ & 59 \\
\hline In patient atherosclerotic plaques & $\begin{array}{l}\text { Based on TLR proteins analyzed with immune-histochemical assay, } \\
\text { increased TLR5 expression was showed in all the observed } \\
\text { atherosclerotic lesions. }\end{array}$ & 59 \\
\hline In atherosclerosis mice model & $\begin{array}{l}\text { Deficiency of TLR5 reduced atherosclerosis due to high fat } \\
\text { ingestion with decreased TLR4 expression. }\end{array}$ & 59 \\
\hline
\end{tabular}


Table I (Continued).

\begin{tabular}{|c|c|c|}
\hline Animal/Human Studies & Findings & Ref \\
\hline In LDLr-I- mice model & $\begin{array}{l}\text { Deficiency of TLR5 in hematopoietic cells showed about a } 25 \% \\
\text { reduction in the lesion of atherosclerosis with decreased } \\
\text { macrophage accumulation and defective } T \text { cell responsiveness }\end{array}$ & 89 \\
\hline Mice aortic ECs and HAECs in vitro models & $\begin{array}{l}\text { TLR5 showed no effect on maturation of macrophages, however, } \\
\text { MCP-I and IL-6 were expressed. Through MyD88-independent } \\
\text { pathway, the interaction of TLR5 with Nox4 to stimulate generation } \\
\text { of peroxide that is induced by bacteria flagellin. Currently, the flagellin- } \\
\text { TLR5-Nox4-NF-kB axis showed to enhance formation of IL-6 and } \\
\text { migration of VSMCs via a JNK-Rho A and Racl pathway. }\end{array}$ & 89,90 \\
\hline In ApoE-I- mice model & $\begin{array}{l}\text { Knocking down of Nox4 saves mice from atherosclerosis in } \\
\text { presence of challenge of TLR5. These findings showed that TLR5- } \\
\text { Nox4-KB axis has a significant role in atherogenesis. }\end{array}$ & 90,91 \\
\hline In patients with acute ischemic stroke & $\begin{array}{l}\text { The amount of TLRs } 7 \text { and } 8 \text { in blood is linked with low outcomes } \\
\text { and higher inflammatory responses implying that these receptors } \\
\text { have a contribution in the pathogenesis of inflammatory diseases. }\end{array}$ & 92 \\
\hline High fat diet fed rabbit model & $\begin{array}{l}\text { There is upregulation of mRNA expression of TLR8 which is linked } \\
\text { with development of atherosclerosis in the aorta, indicating the } \\
\text { importance of the involvement of TLR8 in atherothrombotic }\end{array}$ & 83,93 \\
\hline In IFR5 deficient mice model & $\begin{array}{l}\text { IRF5, mediator in the downstream cascade of TLR7/8/9 in the } \\
\text { TRAF3 signalling. It was investigated that depletion of IFR5 } \\
\text { promotes atherosclerosis; showing the protective biological role of } \\
\text { this protein probably due to enhanced secretion of IL-10 in } \\
\text { response to stimulation of TLR } 9 .\end{array}$ & $94-96$ \\
\hline In vitro and in vivo studies in human platelets & $\begin{array}{l}\text { Because TLR9 is found in human platelets, in vitro studies indicated } \\
\text { that aggregation and activation of platelets I was enhanced while it } \\
\text { promotes thrombosis in vivo in a MyD88 dependent way. }\end{array}$ & 59 \\
\hline In mice Raw264.7 cells & $\begin{array}{l}\text { Activation of TLR9 promotes LOX I and Nox I expression } \\
\text { through TLR9-p38 MAPK signalling pathway, tending to foam cell } \\
\text { formation and TLR9 enhances stimulation of macrophages via } \\
\text { promotes activation of macrophages inj mediating atherosclerosis } \\
\text { and vascular formation. }\end{array}$ & 97,98 \\
\hline In vitro studies in macrophages & $\begin{array}{l}\text { Stimulation of TLR9 in macrophages with a CPG- } \\
\text { oligodeoxynucleotide produces enhanced lipid formation and } \\
\text { augment foam cell generation via a NF-KB and IRF7 dependent way. } \\
\text { Besides, its activation on plaque residing plasmacytoid DCs provokes } \\
\text { increase secretion of IFN- } \alpha \text {, a cytokine associated with instability of } \\
\text { plaque, and enhanced cytotoxicity of CD4 }{ }^{+} \mathrm{T} \text { cells toward SMCs }\end{array}$ & 99,100 \\
\hline In overexpression of TLRI0 cell models and transgenic mice model & $\begin{array}{l}\text { To date, TLRIO is the newly identified receptor of the TLR family in } \\
\text { humans . Because the ligands for TLRI0 have not yet been identified, } \\
\text { the functional role of the receptor has not been well studied. There } \\
\text { are genomic resemblance b/n TLRIO, TLRI and TLR6. } \\
\text { In overexpression of TLRI0 cell models and transgenic mice model, } \\
\text { suppression of TLR signaling was observed. }\end{array}$ & 59 \\
\hline
\end{tabular}


Table I (Continued).

\begin{tabular}{|c|c|c|}
\hline Animal/Human Studies & Findings & Ref \\
\hline Hypertensive pregnant rats and mice & $\begin{array}{l}\text { For instance, in the cases of preeclampsia, the placenta showed } \\
\text { increased necrosis of trophoblastic cells resulting release of } \\
\text { mitochondrial DNA that can act as a candidate ligand for TLR9. } \\
\text { The ligand receptor binding triggers further stimulation of innate } \\
\text { immune cells to result profound maternal inflammation, vascular } \\
\text { dysfunction, leading intrauterine growth restriction and } \\
\text { hypertension. } \\
\text { Experimental finding revealed that preeclampsia like syndrome is } \\
\text { manifested in mice due to lack of anti-inflammatory IL-10 and it is } \\
\text { also suggested that ligands for TLR3 like viral mimetic cause } \\
\text { endothelial dysfunction, proteinuria and hypertension in rats and } \\
\text { mice during pregnancy. }\end{array}$ & 101 \\
\hline Hypertensive pregnant rats and mice & $\begin{array}{l}\text { Experimental findings in spontaneously hypertensive rat revealed } \\
\text { that anti-TLR4 antibody for I5 days reduced blood pressure, IL-6 } \\
\text { levels in the serum and TLR } 4 \text { protein in the arteries. } \\
\text { A study showed that angiotensin II also exhibits central role in } \\
\text { stimulating the immune response, up regulating TLRs } 2 \text { and } 4 \text {. The } \\
\text { innate immune system, especially the TLRs, have been distinguished } \\
\text { to play a significant contribution for the resulted hypertension. } \\
\text { There are also studies supporting the main contribution of the } \\
\text { innate immune receptors, particularly of TLR7, to be a pivotal } \\
\text { regulator of immune complex mediated glomerulonephritis. }\end{array}$ & 84 \\
\hline
\end{tabular}

TLRs, except TLR3, and provokes the generation of inflammatory cytokines while the MyD88 independent pathway (TRIF-dependent pathway) is utilized by TLRs 3 and 4 and is related to the activation of type I interferon. TLR signaling occurs by the expression of the different types of TLRs and their specificity is achieved by their ability to recognize ligands and involvement of adapter proteins. Therefore, the specificity of pathway selection during disease condition may result various outcomes that can differentiate the phenotype of tissue injury or organ damage. ${ }^{33}$

\section{Implications of TLRs in Diabetes with Direct Effect on $\beta$ Cells}

Diabetes is also distinguished with a low grade inflammatory condition within islet cells that is assumed to be a major determinant in $\beta$ cell dysfunction and have a role in the pathogenesis of the disease. However, to what extent inflammation will have a role and the mediators, and using antiinflammatory therapies as a potential target have not yet been studied. Currently, the role of TLRs in the pathogenesis of diabetes has begun to be unveiled as far as these receptors are largely expressed in a variety of immune cells. ${ }^{34}$

\section{Role of TLR Signalling in $\beta$-Cell Function and Glucose Homeostasis}

TLRs have been identified as involved in mediating chronic inflammatory disease, such as obesity and diabetes. These known receptors are found in a variety of cells including the pancreatic islets. Glucose and SFAs contribute the expression of TLR and their activation in human monocytes, as the cell surface expression of TLR4 is upregulated where there is a high level of glucose and SFAs can provoke generation of inflammatory cytokine through TLR $4 .{ }^{35}$ On the contrary, lack of TLR4 prevents mice from high fat diet induced obesity. ${ }^{36}$ Investigations conducted to examine the role of MyD88 in glucose homeostasis using mice deficient with MyD88 showed that mice have normal glucose tolerance and fasting blood glucose levels with a decreased $\beta$ cell mass compared to the wild-type controls. ${ }^{37}$ Studies showed that the TLR signalling could contribute in the generation and/or replication of $\beta$ cells. Moreover, it was also indicated that when mice treated with a multiple low dose of streptozotocin (STZ) so as to elicit $\beta$ cell death, mice lacking MyD88 were shown to have glucose intolerance. ${ }^{35}$ 


\section{TLR2/4 Deficiency in $\beta$ Cell Mass}

TLRs cascading stimulate innate immunity by initiating the release of chemokine and cytokine release through upregulation of co-stimulatory molecule expression along with a combination of other effects. ${ }^{38}$ Few studies showed the role of TLR expression on islets, especially TLR 2 and TLR 4, that are involved in the generation of an autoimmune diabetes and allogeneic islet transplant rejection. ${ }^{39-41}$ TLR2/4 initiated a pro-inflammatory milieu, probably through release of chemokine and cytokine at the site of the graft, linked with graft apoptosis and early grafts. ${ }^{38}$ Collectively, studies indicated that TLR signalling has a role in inflammatory responses due to pre-implantation injuries of pancreatic islets. Similarly, it was also observed that cultured islets showed a pro-inflammatory and pro-oxidant phenotype identified with a high amount of pro-inflammatory markers. In addition, the inflammatory responses have been partially dependent on TLR signalling during low defense mechanisms and further blockage of TLR4. ${ }^{38}$

The abnormal clearance and resultant aggregation of apoptotic cells can elicit autoimmunity; however, the mechanism of action has not been clearly understood. In line with these processes, it was indicated that apoptotic cells can undertake secondary necrosis but not intact apoptotic cells induce such remarkable immune responses, which are mediated by the TLR2 pathway. The generation of autoimmune diabetes was largely reduced in TLR2-/- mice when compared to TLR4-/mice, implying that TLR2 plays an important role in initiating the disease. Injury of $\beta$ cell due to apoptosis provokes the priming of diabetogenic T cells via a TLR2 dependent, but TLR4 independent activation of APCs. These findings suggested that damage to $\beta$ cell and sensing by TLR 2 could be a starting point for the activation of APCs and generation of autoimmune DM. ${ }^{42}$

The expression of TLR4 in the islets of Langerhans has been documented as deleterious in both murine and human $\beta$ cells. Exposure to LPS induces a loss of $\beta$ cells and decreases the synthesis and secretion of insulin. Moreover, it has been observed that the sera of type 1 diabetic patients exhibit increased levels of endogenous TLR4 ligands, such as endotoxins, HSP60 and HMGB116. TLR4 expression is also upregulated on monocytes from type 1 diabetic patients. ${ }^{43}$ Additionally, in a human cell model, CXCL10, through TLR4 signalling, induces $\beta$ cell death and dysfunction. ${ }^{44}$ Taken together these data provide convincing evidence for the deleterious effects on B cells mediated by TLR4 activation. Because of these considerations, it was explored whether TLR4 blockade could prevent the development of insulitis and the onset of autoimmune diabetes in NOD mice. Using CLI-095, a cyclohexene derivative that inhibits TLR4 signalling, it was possible to observe a protective effect mediated by the decreased activation and proliferation of the diabetogenic autoreactive $\mathrm{CD} 4+$ $\mathrm{T}$ lymphocytes as well as IFN-g production by these cells, both in the pancreatic lymph nodes and in the spleen, and consequently the inhibition of the autoimmune process. Interestingly, this was specifically observed in CD4, but not CD8 T cells. ${ }^{45}$

\section{Implication of TLRs in Macrophage Polarization, Obesity and Inflammation}

Among the promising and emerging treatment mechanisms for both types of diabetes, cellular replacement and regeneration therapeutics are those being investigated. In animal and human studies, maintenance of $\beta$ cells in the pancreas are accomplished by the process of neogenesis of $\beta$ cells from the ductal precursor cells and replication of the preexisting $\beta$ cells. Neogenesis usually occurs during fetal and neonatal life, and the rate of $\beta$ cell proliferation shows a dramatic reduction with age. Renewal of $\beta$ cells or mitotic replication of $\beta$ cells compensates the rise in metabolic need in adults. The western diet or high fat diet (HFD) elicits a mild proliferation of $\beta$ cells and expansion of islet mass; but the mechanism of action provoking this adaptive mechanism is still elusive. In obesity induced by high fat diet the raised metabolic burden enhances release of insulin by promoting its secretion per $\beta$ cell and/or by increasing the number of $\beta$ cell. Insulin and glucose, growth factors and nutrients enhance the replication of $\beta$ cell, partially by stimulating pro-proliferative or prosurvival protein kinases such as Akt and Erk (or MAPK, mitogen-activated protein kinase). Stimulation of Akt and Erk-MAPK probably initiates proliferation of $\beta$ cell via activation of cell cycle regulators such as the cyclin D2 and Cdk4 and/or anti-apoptotic factors that suggest potentially the negative regulation in limiting diet induced $\beta$ cell replication, however, the exact identity remains largely not understood. TLR proteins show the linkage of innate immunity to adaptive immune responses against disease causing pathogens like viruses, fungi, bacteria, and protozoa. From the various TLR proteins, TLR4 can detect LPS 
found in most $\mathrm{G}^{-\mathrm{ve}}$ bacteria, while TLR2 in connection with TLR1/6 recognize lipopeptides and other components of $\mathrm{G}^{+\mathrm{ve}}$ bacteria. It was showed that TLRs 2 and 4 may mediate nutrient sensing and metabolic regulation in type 2 diabetes by their direct or indirect action as sensors for FAs or other lipids in adipose tissue and macrophages. ${ }^{46}$ Studies reported that, knocking out of either TLR2/4 in mice fed HFD decreases systemic inflammation in the liver and adipose tissue, and improves insulin sensitivity. However, TLR2-/- and 4-/- mice on HFD show mild metabolic phenotypes in terms of glucose and insulin sensitivity that could be described by the redundant function of TLRs 2 and 4. ${ }^{47-51}$

In addition, it was also shown that TLRs 2 and 4 regulated the proliferation of $\beta$ cell. In mice and humans, TLRs 2 and 4 mediated signalling pathways in combination can maintain $\beta$ cell quiescence in an islet-intrinsic manner. Knocking out of TLRs 2 and 4, but not either of these receptors separately increased the proliferation of $\beta$ cells in a HFD dependent manner. The synergy because of the combined action of adipocytes and macrophages is a key process in the maintenance of obesity led adipose tissue inflammation and the resultant insulin resistance. Adipocytes and immune cells may have cell specific contributions in that the mechanism by which proinflammatory mediators influence adipogenesis is probably due to the direct stimulation of NF- $\kappa$ B pathway that thereby impairs the activity of PPAR $\gamma$ in the process of adipocyte differentiation. The previous and current evidences correlate TLR4 with inflammation induced by lipid through the action of LPS. In case of obesity and metabolic syndrome, adipose tissue often shows dysregulation in the process of adipogenesis, and hence results in inflammation and metabolic dysfunction. Studies demonstrated that TLR4 might not elicit a potent inflammatory response to LPS, rather mediators as a result of metabolism of adipocytes could contribute adipocyte-immune cell inflammatory linkage in a TLR4 dependent and independent manner. ${ }^{52}$

\section{TLRs in Transplantation}

TLRs have a well-distinguished linkage between innate and adaptive immunity and typically can recognize exogenous ligands such as LPS, besides its ability to sense endogenous ligands, generally, known as DAMPs, such as key molecules involved in an autoimmune diseases or necrotic cell products, usually released during injury in organ or cell transplantation. ${ }^{43}$ The involvement of TLRs in the conventional T cells was investigated to enhance the survival of $\mathrm{T}$ cells and can co- stimulate these cells while engagement of TLRs in regulatory $T$ cells was reported to either promote or inhibit their suppressive potential. Based on targeted tissue and positioning of TLRs (apical/basolateral), their binding on endothelial cells and pericytes exhibits enhancement in vascular leakage while their involvement on epithelial cells probably have antiinflammatory or pro-inflammatory effects. All the abovementioned cells play significantly in recognizing immune responses to transplanted organs, implicating the important role of TLR signalling in regulating transplant rejection and tolerance.

The role of TLR signalling in acute allograft rejection and prevention of the induction of transplantation tolerance by co-stimulatory targeted therapies is substantial. Besides, some evidence implicated that TLR signals were also shown to have a role in xenograft rejection, graft vs host disease (GVHD) and the development of chronic rejection. Basically, the TLR polymorphism and further genetic analysis of the effects of the polymorphism on the outcome of transplanted grafts support their clinical importance. In investigating the probable mechanisms, the pro-rejection activities of TLRs have been correlated to hindering the deletion of alloreactive $\mathrm{T}$ cells, enhancement of Th1 differentiation, decreased intragraft migration of regulatory $\mathrm{T}$ cells and secretion of type I interferon which can further provokes multiple immune consequences. ${ }^{53}$

\section{TLRs and Diabetic Complications TLRs in Cardiovascular Complications}

Cardiovascular disorders are among the most common macrovascular complications of DM. The higher proportion of mortality of diabetic patients is attributed to various cardiovascular complications such as CAD, cerebrovascular disease, peripheral vascular problems, and stroke. From these complications, the majority of deaths are a result of coronary artery disease which is mostly caused by atherosclerosis. Because these complications contributed to the majority of deaths in diabetic patients, understanding of the pathological mechanisms, possible drug targets and scrutiny of suitable therapeutic strategies are of the great concern for the scientific community. A detailed knowledge of the pathological mechanisms of TLRs with regard to the cardiovascular complication will have paramount importance. In addition to the immune cells, expressions of TLRs are also observed in other 
cells found in the epithelium, endothelium, adipocytes, and the cardiovascular system. ${ }^{54}$

The expression of messenger RNA for TLR1-10 has been detected in the human heart. Different studies suggested that temporal or short-term activation of TLRs has cardio-protection, while prolonged or excessive activation of TLRs triggers chronic low grade inflammation leading to endothelial dysfunction, increased cell death, adverse cardiac remodeling and a subsequent coronary and cerebrovascular atherosclerosis, heart failure, septic cardiomyopathy, viral myocarditis, valvular diseases, thrombosis and/or hypertension. ${ }^{55,56}$ To date, the cardiovascular research field is giving greater concern in this receptors family, provided that the receptors are expressed in most cardiovascular cells including cardiomyocytes, endothelial cells, adventitial fibroblasts, macrophages and dendritic cells. ${ }^{57}$ Atherothrombotic disease is another complication resulting in $\mathrm{CAD}$, which still requires a better treatment strategy. Promising treatment approaches targeting the TLR system (as presented in Table 1) will potentially affect the inflammatory pathways so that it delays progression of atherosclerosis and decreases the consequences of CAD. Because most of the recent investigations still rely on in vitro and animal models, challenges occur when findings are translated to humans. Further studies regarding the role of each TLR with their molecular mechanisms, including the effect of its downstream pro- nflammatory cytokines, are highly needed to advance the area. Therefore, targeting a selected receptor or an intermediate or product of cytokines could help the discovery of an efficacious agent in the prevention of atherothrombotic CAD. ${ }^{58-61}$

\section{TLRs in Angiogenesis}

Angiogenesis, a physiologic process in the formation of new blood vessels, is regulated by chemical signals in the body and is a mechanism protecting organs against danger and tissue necrosis. There is activation of inflammatory cascading pathways even without the presence of infection and this signaling is assumed to involve angiogenesis during wound healing. In ischemic tissue necrosis of cells produce DAMPs which can activate TLR2. A study demonstrated that stimulation of TLR2 could promote tubular formation, in addition to endothelial cell invasion and migration promoted angiogenesis in vitro and in vivo and these findings give impetus for a scientific concern that TLR2 is viewed as a potential novel target in the treatment of ischemic disease. ${ }^{62}$

\section{TLRs in Nephropathy}

Diabetic nephropathy (DN) is one of the major complications of chronic renal disease, distinguished by renal failure with podocyte loss, thickening of glomerular basement membrane, tubular dysfunction, and expansion of the mesangium, which is composed of extracellular matrix proteins from mesangial cells around glomerular capillaries. Because of the excess, DN causes occlusion of glomerular capillaries, however, the mechanism of action has not yet been understood. ${ }^{63}$ Although DN is generally assumed to be a noninflammatory condition, there is emerging evidence supporting that the innate immune mechanism and inflammatory cascades have substantial contribution in the generation and progression of $\mathrm{DN}$. For instance, the impairment of renal function in patients with DM with proteinuria has shown a direct link with tubule interstitial inflammation. ${ }^{62,64}$

To date, TLRs have been identified as one cause in the emergence of DN. Basically, components of $\mathrm{G}^{+\mathrm{ve}}$ bacterial like lipoteichoic acid are sensed by TLR 2 and components of the $\mathrm{G}^{-\mathrm{ve}}$ bacterial like LPS are sensed by TLR4, and LPS from the periodontal pathogen porphyromonas gingivalis binds TLRs 2 and 4. A hyperglycemic state of at least $11.2 \mathrm{mM}$ glucose (diagnostic reference point for DM), and free fatty acid increase the level of TLRs 2 and 4 in monocytes, glomeruli, and proximal tubules in DN. The TLR ligand engagement provokes the production of proinflammatory cytokines like TNF-a and IL-6, and also production of anti-inflammatory cytokines like transforming growth factor-b (TGF-b), and the cytokines and hence enhances the overproduction of mesangial matrix, such as type I collagen. Based on current investigations, it was assumed that metabolic diseases, inflammation, oxidative stress, hemodynamic changes, and other contributory factors are blamed for the generation of $\mathrm{DN} .{ }^{63}$

\section{TLR2 and TLR4 and Inflammation in DN}

TLR4 is mainly found in intrinsic renal cells like mesangial cells, tubular epithelial cells, and podocytes. Previous investigations have shown that TLR4 acts to upregulate noninflammatory kidney disease such as renal ischemia reperfusion injury, tubule-interstitial nephritis, and glomerulonephritis besides its active involvement in the emergence and progression of DN. Furthermore, much emerging evidence suggested that stimulation of TLR4 has a role in the process of inflammation. Because of their stimulatory effect when interacted with generated 
endogenous ligands in the kidney and immune cells, TLR4 activates the downstream signalling pathway through MyD88 dependent and independent pathways, and leads to the activation of NF- $\kappa B$, The activated NF- $\kappa B$ consequently joins to the nucleus and initiates transcription and translation of inflammatory genes to transcription and translation of genes involved in inflammatory process, to end up with a rise in the release of pro-inflammatory cytokines and chemokines like monocyte chemoattractant protein- (MCP-) 1, IL-6/8/18, TNF- $\alpha$. As a biomarker of $\mathrm{DN}, \mathrm{NF}-\kappa \mathrm{B}$ is identified to be engaged in other pathological mechanisms in addition to the accumulation of advanced glycation end products, stimulation of renin angiotensin system and protein kinase $\mathrm{C}$ (PKC), and oxidative stress. ${ }^{65}$ Recent findings indicated that knocking out of TLR4 reduces renal inflammation, fibrosis, and podocytopathy. Moreover, prior investigations demonstrated that in patients with type $1 \mathrm{DM}$, there exists an enhanced expression and activity of TLR4 on monocytes, which is found to be prominent during DN. Moreover, it was observed that genetic deficiency of TLR4 attenuates systemic and macrophage inflammation in type 1 diabetes. ${ }^{64}$

Several investigations using TLR4-/- and TLR 2-/mice showed that, blockade of TLR2/4 could have a cytoprotective effect in AKI and CKD models. In the same way, findings illustrated that TLR4 expressed in parenchymal renal cells, not on myeloid cells involved in renal inflammation and injury in cisplatin induced AKI, and TLR4-/- mice potentially reduce levels of cytokines in serum, kidney and urine, and showed a lower histologic damage when compared to wild type mice. In TLR2-/mice and antisense oligonucleotide, it was indicted that TLR2 blockage showed protection to renal $I / R$ injury. During renal fibrosis, TLR4-/- mice revealed to unilateral ureteral obstruction showed a lower tubular fibrosis, but not myofibroblast accumulation. ${ }^{66}$

Renal inflammation may also be observed in many other kidney diseases which are considered noninflammatory including diseases such as DM. Whatever the cause, tissue damage could result in inflammation. In the case of tissue damage caused by a nonpathogen the triggered inflammation, certain intracellular molecules produced during renal cell death and other extracellular molecules, ligate the same danger sensors of the innate immune system. TLRs, innate pathogen sensors, currently viewed as potential sensors to be targeted in this regard. On the cell surface (TLR1/2/4/5/6) or in the intracellular endosomes (TLR3/7/8/9) TLRs can recognize the entire spectrum of potential pathogens by ligating the so-called PAMPs, like LPS (TLR4), lipopeptides (TLR1/2/6), and viral/bacterial nucleic acids (TLR3/7/8/9). The expression of TLRs 2 and 4 was increased in adipose tissue and muscle of humans and in animal models of insulin resistance. Currently, the exact mechanism of TLRs 2 and 4 in tubule interstitial inflammation during DM remains unknown and requires further investigation. ${ }^{67,68}$ In patients with DM, hyperglycemia, circulating endotoxins, and DAMPs like proteins and free fatty acid aids the response of TRRs. Expressions of TLRs 2, 4, 5, 7, 8, and 9 were identified to present in diabetic renal samples in which TLRs 2 and 4 were the most widely investigated. Blocking TLRs 2 and 4 in mice has shown renal benefits, while their role in humans is still under investigation and additional study is required to delineate the role in renal injury. ${ }^{69}$

\section{TLRs in Diabetic Foot Ulcer}

The hyperglycemic state and increased free fatty acids initiates pro-inflammatory cytokines in diabetes and this interaction is an implication for the immune system to take part in that way. Aggregated evidence showed that inflammatory conditions and bacterial colonization around the areas of injury are the major contributing factors to delay time of regeneration or healing of the ulcer or not at all. TLRs in and around the wound participate in regulating the functioning of the innate immune system and the production of inflammation. Investigations in humans and animals have indicated that inflammation is one major etiology in the pathogenesis of diabetes and principally the effect is linked to the innate immune receptors. ${ }^{42}$

According to a study, ${ }^{70}$ it was demonstrated that increment in the expression of TLRs 2 and 4 in bone marrow derived macrophages of nonobese diabetic mice were associated with activation of NF- $\kappa \mathrm{B}$ and proinflammatory cytokines. With a study ${ }^{71}$ using TLRs 2 and 4 knockout mice and nonobese diabetic mice have showed that TLR2 senses B cell death and provokes the emergence of autoimmune diabetes. It was showed that increased TLR2 expression in adipose tissue of type 2 diabetic patients had a strong linkage with plasma endotoxin levels. ${ }^{72}$ It was reported with a study ${ }^{24}$ that increased TLR4 mRNA expression in differentiating adipose tissue of diabetic mice. In addition to the above studies, it was also shown that a TLR4-deficient mouse strain fed with a diet rich in saturated fat is protected from systemic inflammation. The aggregated data taken together 
suggested that TLR2 and TLR4 have a potential role in the pathology of DM. Sustained and exacerbated production of cytokines leads to sustained inflammatory responses and impairment of wound healing which causes extensive tissue damage and amputations during diabetic wounds. As a result, understanding local inflammatory mechanisms is important in establishing other potential therapeutic modalities in the management of severe wounds exacerbated due to excessive inflammation. ${ }^{42}$

\section{TLRs in Diabetic Retinopathy}

DR is among the microvascular complications as a result of hyperglycemic state in diabetes. One of the possible mechanisms of a hyperglycemic condition in the induction of DR is increased inflammation among many others. Several studies have reported that inflammation has a role in the development of DR. ${ }^{73-75}$

Based experimental investigations, it was revealed that TLRs 2 and 4 can promote inflammation and thereby play a role in the pathogenesis of DR. Besides the upregulation of TLRs 2 and 4, studies also revealed that the use of different inhibitors decreased the TLR-mediated inflammation. The observation clarified that both TLRs 2 and 4 are provoked by increased in microvascular retinal endothelial cells and might probably contribute to DR by inducing increased inflammation. ${ }^{76}$ In the condition of diabetic retinopathy, TLRs initiate immunological damage to retinal cells by regulating a mass of cytokines and co-stimulatory molecules besides provoking oxidative damage to DNA. ${ }^{77}$

\section{TLRs in Diabetic Neuropathy}

Neuropathy is another most commonly encountered complication of DM that results a sustained loss of nerve function. Dysregulation of the immune system and low level systemic inflammatory conditions are linked with obesity and are responsible for further progression of metabolicdysfunction. Findings suggested that pathways of TLRs 2 and 4 play a role in the emergence of neuropathy, implying their potential role in inflammation in neuropathy next to pre-diabetes and diabetes. ${ }^{78}$ In addition, upregulation of TLRs 2 and 4 was observed during neuropathic pain and hence blockade of TLRs 2 and 4 produced analgesia and moreover enhanced the effectiveness of buprenorphine. ${ }^{79}$

\section{Conclusion and Future Perspectives}

An increased and ongoing investigation regarding the mechanisms relating inflammation brings great attention in viewing inflammatory cascades as potential and promising approaches in the prevention and control of DM and associated complications. Research in this area will have paramount importance to provide evidence and a more detailed knowledge of the immune system, not merely to better identify patient characteristics and identify potential therapeutic modality, but importantly to fully elaborate the pathophysiological basis of disease and possible drug targets, thereby easing the development of new strategies to counteract disease development and progression. Considering many illustrative reviews of the possible mechanisms involved in both types of diabetes and the numerous inflammatory cascades that are taking part, the current research direction should provide greater emphasis on blockage of responsible inflammatory components in the cascading pathway. TLRs are among the emerging targets to be investigated in consideration of target diseases immunotherapy since these receptors are capable of exacerbating inflammatory disorders. ${ }^{28,79,80}$

In conclusion, it is important to be certain to have sufficient and large-scale clinical trial data in order to guide the research community and provide evidence in refining drug targets in the pathophysiological manifestations of diabetes and discovery of newer agents in treating diabetes and its complications. Applying a combination of computational power, next-generation sequencing and proteomic data and increased number of investigations probably will have a dramatic rise in the search for novel therapeutic approaches for many inflammatory disorders employing TLRs in the pathophysiological mechanism.

\section{Disclosure}

The author reports no conflicts of interest in this work.

\section{References}

1. American Diabetes Association. Diagnosis and classification of diabetes mellitus. Diabetes Care. 2012;35(Supplement_1):S64-71. doi:10.2337/dc12-s064

2. Ganie MA, Kotwal S. Recent advances in management of diabetes mellitus. JIMSA. 2012;25(3):171-175.

3. Piero MN, Nzaro GM, Njagi JM. Diabetes mellitus - a devastating metabolic disorder. AJBPS. 2014;4(40):1-7. doi:10.15272/ajbps. v4i40.645

4. Whiting DR, Guariguata L, Weil C, Shaw J. IDF diabetes atlas: global estimates of prevalence of diabetes for 2011 and 2030. Diabetes Res Clin Pract. 2011;94(3):311-321. doi:10.1016/j.diabres.2011.10.029

5. Paul D, Paul K. Diabetes mellitus and its complications: a review. Int $J$ Curr Pharm Res. 2012;4(2):12-17.

6. Sayin N, Kara N, Pekel G. Ocular complications of diabetes mellitus. Ocular complications of diabetes mellitus. World J Diabetes. 2015;6 (1):92-108. doi:10.4239/wjd.v6.i1.92 
7. Umanath K, Lewis JB. Update on diabetic nephropathy: core curriculum. Am J Kidney Dis. 2018;71(6):884-895. doi:10.1053/ j.ajkd.2017.10.026

8. Syafril S. Pathophysiology diabetic foot ulcer. Earth Environ Sci. $2018 ; 125$

9. Virella G, Maria F, Lopes-Virella MF. The role of the immune system in the pathogenesis of diabetic complications. Front Pharmacol. 2014;5(126).

10. Forouhi NG, Wareham NJ. Epidemiology of diabetes. Medicine. 2014;12(42):698-702. doi:10.1016/j.mpmed.2014.09.007

11. Mulatu HA, Bayisa T, Berhe T, Woldeyes E. Pattern of antihypertensive treatment and blood pressure control among diabetic outpatients in Addis Ababa, Ethiopia. J Diabetes Metab. 2017;8 (4):1-4. doi:10.4172/2155-6156.1000738

12. Tracey ML, Gilmartin M, O'Neill K, et al. Epidemiology of diabetes and complications among adults in the Republic of Ireland 1998-2015: a systematic review and meta-analysis. BMC Public Health. 2016;16(1).

13. Bos M, Agyemang C. Prevalence and complications of diabetes mellitus in Northern Africa, a systematic review. BMC Public Health. 2013;3(1).

14. Nigatu T. Epidemiology, complications and management of diabetes in Ethiopia: a systematic review. $J$ Diabetes. 2012;4 (2):174-180.

15. Sakthiswary R, Zakaria Z, Das S. Diabetes mellitus: treatment challenges and the role of some herbal therapies. Middle East J Sci Res. 2014;20(7):786-798.

16. Obimba KC, Belonwu CD, Eziuzor CS. Prophylaxis and treatment of types 1 and 2 diabetes mellitus. Int J Dis Disord. 2014;2 (6):065-073.

17. Scheen A, Paquot N. Metformin revisited: a critical review of the benefit-risk balance in at-risk patients with type 2 diabetes. Diabetes Metab. 2013;39(3):179-190. doi:10.1016/j.diabet.2013.02.006

18. Mihailova S, Tsvetkova A, Todorova A. Pharmacological trends in the treatment of diabetes type II: new classes of antidiabetic drugs. Int Arch Med. 2015;2(4):223-228.

19. Pino SC, Kruger AJ, Bortell R. The role of innate immune pathways in type 1 diabetes pathogenesis. Curr Opin Endocrinol Diabetes Obes. 2010;17(2):126-130. doi:10.1097/MED.0b013e3283372819

20. Massimo P, Julie MS, Patrick WN, George SE. Primer: immunity and autoimmunity. Diabetes. 2008;57(11):2872-2882. doi:10.23 37/db07-1691

21. Cen X, Liu S, Cheng K. The role of toll-like receptor in inflammation and tumor immunity. Front Pharmacol. 2018;9(878). doi:10.3389/fphar.2018.00878

22. Lee MS. Role of innate immunity in diabetes and metabolism: recent progress in the study of inflammasomes. Immune Netw. 2011;11(2):95-99. doi:10.4110/in.2011.11.2.95

23. Tong Zhou T, Hu Z, Yang S, Sun L, Yu Z, Wang G. Role of adaptive and innate immunity in type 2 diabetes mellitus. J Diabetes Res. 2018;2018:1-9. doi:10.1155/2018/7457269

24. Goldberg RB. Cytokine and cytokine-like inflammation markers, endothelial dysfunction, and imbalanced coagulation in development of diabetes and its complications. J Clin Endocrinol Metab. 2009;94(9):3171-3182.

25. Kolb H, Herrath MV. Immunotherapy for type 1 diabetes: why do current protocols not halt the underlying disease process? Cell Metab. 2017;25(2):233-241. doi:10.1016/j.cmet.2016.10.009

26. Ludvigsson J. Therapies to preserve b-cell function in type 1 diabetes. Drugs. 2016;76:169-185.

27. De Candia P, Prattichizzo F, Garavelli S, et al.Type 2 diabetes: how much of an autoimmune disease? Front Endocrinol (Lausanne). 2019;10(451):1-14.

28. Bianca K, Thomas M. Stulniga, autoimmune aspects of type 2 diabetes mellitus - a mini-review. Gerontology. 2014;60 (3):189-196. doi:10.1159/000356747
29. Piero NM, Murugi NJ, Okoth OR, et al. Prevention of type i diabetes mellitus: the role of immune interventions. J Clin Cell Immunol. 2012;S2:005.

30. Kawasaki T, Taro Kawai T. Toll-like receptor signaling pathways. Front Immunol. 2014;5(461):1-8.

31. Jialal I, Kaur H, Devaraj S. Toll-like receptor status in obesity and metabolic syndrome: a translational perspective. $J$ Clin Endocrinol Metab. 2014;99(1):39-48. doi:10.1210/jc.2013-3092

32. El-Zayat SR, Sibaii H, Mannaa FA. Toll-like receptors activation, signaling, and targeting: an overview. Bull Natl Res Cent. 2019;43 (187):1-12. doi:10.1186/s42269-019-0227-2

33. Adamczak DM. The role of toll-like receptors and vitamin D in cardiovascular diseases-a review. Int J Mol Sci. 2017;18 (2252):1-23. doi:10.3390/ijms18112252

34. Bazi A. Toll-like receptors and targeted therapy in diabetes mellitus. Int J Basic Sci Med. 2017;2(2):71-72.

35. Meredith JH, Hutton GS, Johnson JD, Bruce Verchere C. Role of the TLR signaling molecule TRIF in $\beta$-cell function and glucose homeostasis. Islets. 2010;2(2):104-111. doi:10.4161/isl.2.2.11209

36. Shi H, Kokoeva MV, Inouye K, Tzameli I, Yin H, Flier JS. TLR4 links innate immunity and fatty acid-induced insulin resistance. J Clin Invest. 2006;116(11):3015-3025. doi:10.1172/JCI28898

37. Bollyky PL, Bice JB, Sweet IR, et al. The toll-like receptor signaling molecule Myd88 contributes to pancreatic beta-cell homeostasis in response to injury. PLoS One. 2009;4(4):5063. doi:10.1371/journal.pone.0005063

38. Vivot K, Langlois A, Bietiger W, et al. Pro-inflammatory and pro-oxidant status of pancreatic islet in vitro is controlled by TLR-4 and HO-1 pathways. PLoS One. 2014;9(10):e107656.

39. Wen L, Peng J, Li Z, Wong FS. The effect of innate immunity on autoimmune diabetes and the expression of Toll-like receptors on pancreatic islets. J Immunol. 2004;172(5):3173-3180. doi:10.40 49/jimmunol.172.5.3173

40. Vives-Pi M, Somoza N, Fernandez-Alvarez J, et al. Evidence of expression of endotoxin receptors CD14, toll-like receptors TLR4 and TLR2 and associated molecule MD-2 and of sensitivity to endotoxin (LPS) in islet beta cells. Clin Exp Immunol. 2003;133 (2):208-218. doi:10.1046/j.1365-2249.2003.02211.x

41. Goldberg A, Parolini M, Chin BY, et al. Toll-like receptor 4 suppression leads to islet allograft survival. FASEB J. 2007;21 (11):2840-2848. doi:10.1096/fj.06-7910com

42. Kim HS, Han MS, Chung KW, Kim S, Kim E. Toll-like receptor 2 senses $b$ cell death and contributes to the initiation of autoimmune diabetes. Immunity. 2007;27(2):321-333. doi:10.1016/j. immuni.2007.06.010

43. Alibashe-Ahmed M, Berney T, Giovannoni L, Berishvili E. Targeting toll-like receptor 4: a promising strategy to prevent type 1 diabetes occurrence or recurrence. CellR4. 2020;8: e2850.

44. Schulthess FT, Paroni F, Sauter NS, et al. CXCL10 impairs $\beta$ cell function and viability in diabetes through TLR4 signaling. Cell Metab. 2009;9(2):125-139. doi:10.1016/j.cmet.2009.01.003

45. Alibashe-Ahmed M, Brioudes E, Reith W, Bosco D, Berney T. Toll-like receptor 4 inhibitions prevents autoimmune diabetes in NOD mice. Sci Rep. 2019;9(1):19350. doi:10.1038/s41598-01955521-Z

46. Ji Y, Sun S, Shrestha N, Darragh LB, Shirakawa J. Toll-like receptors TLR2 and TLR4 block the replication of pancreatic $\beta$ cells in diet-induced obesity. Nat Immunol. 2019;20(6):677-686.

47. Himes RW, Smith CW. Tlr2 is critical for diet-induced metabolic syndrome in a murine model. FASEB J. 2010;24(3):731-739. doi:10.1096/fj.09-141929

48. Razolli DS, Moraes JC, Morari J, et al. TLR4 expression in bone marrow-derived cells is both necessary and sufficient to produce the insulin resistance phenotype in diet-induced obesity. Endocrinology. 2015;156(1):103-113. doi:10.1210/en.2014-1552 
49. Vila IK, Badin P-M, Marques M-A, et al. Immune cell Toll-like receptor 4 mediates the development of obesity- and endotoxemia-associated adipose tissue fibrosis. Cell Rep. 2014;7 (4):1116-1129. doi:10.1016/j.celrep.2014.03.062

50. Jia L, Vianna CR, Fukuda M, et al. Hepatocyte toll-like receptor 4 regulates obesity-induced inflammation and insulin resistance. Nat Commun. 2014;5(1):3878. doi:10.1038/ncomms4878

51. Lee CC, Avalos AM, Ploegh HL. Accessory molecules for toll-like receptors and their function. Nat Rev Immunol. 2012;12:168-179.

52. McKernan K, Varghese M, Patel R, Singer K. Role of TLR4 in the induction of inflammatory changes in adipocytes and macrophages. Adipocyte. 2020;9(1):212-222. doi:10.1080/2162 3945.2020.1760674

53. Alegre ML, Chong A. Toll-like receptors (TLRs) in transplantation. Front Biosci (Elite Ed). 2015;1:36-43.

54. Vallejo JG. Role of toll-like receptors in cardiovascular diseases. Clin Sci. 2011;121(1):1-10. doi:10.1042/CS20100539

55. Dekleijn D, Pasterkamp G. Toll-like receptors in cardiovascular diseases. Cardiovasc Res. 2003;60(1):58-67.

56. Kleijn DD, Pasterkamp G. Toll-like receptors in cardiovascular diseases cardiovascular research. Cardiovasc Res. 2003;60 (1):58-67. doi:10.1016/S0008-6363(03)00348-1

57. Zhou Y, Little PJ, Downey L, et al. The role of toll-like receptors in atherothrombotic cardiovascular disease. ACS Pharmacol Transl Sci. 2020;3(3):457-471. doi:10.1021/ acsptsci.9b00100

58. Mullick AE, Soldau K, Kiosses WB, Bell TA, Tobias PS, Curtiss LK. Increased endothelial expression of toll-like receptor 2 at sites of disturbed blood flow exacerbates early atherogenic events. J Exp Med. 2008;205(2):373-383. doi:10.1084/jem.2007 1096

59. Mullick AE, Tobias PS, Curtiss LK. Modulation of atherosclerosis in mice by toll-like receptor 2. J Clin Invest. 2005;115 (11):3149-3156. doi:10.1172/JCI25482

60. Curtiss LK, Blac AS, Bonnet DJ, Tobias PS. Atherosclerosis induced by endogenous and exogenous toll like receptor (TLR) 1 or TLR6 agonists. J Lipid Res. 2012;53(10):2126-2132. doi:10. 1194/jlr.M028431

61. Madan M, Amar S, Giannobile W. Toll-like receptor-2 mediates diet and/or pathogen associated atherosclerosis: proteomic findings. PLoS One. 2008;3(9):e3204. doi:10.1371/journal.pone. 0003204

62. Lin M, Yiu WH, Wu HJ. Toll-like receptor 4 promotes tubular inflammation in diabetic nephropathy. J Am Soc Nephrol. 2012;23 (1):86-102. doi:10.1681/ASN.2010111210

63. Sawa Y, Takata S, Hatakeyama Y, Ishikawa H, Tsuruga E, Wang T. Expression of toll-like receptor 2 in glomerular endothelial cells and promotion of diabetic nephropathy by porphyromonas gingivalis lipopolysaccharide. PLoS One. 2014;9(5):e97165. doi:10.1371/journal.pone.0097165

64. Devaraj S, Tobias P, Jialal I. Knockout of toll-like receptor-4 attenuates the pro-inflammatory state of diabetes. Cytokine. 2011;55(3):441-445. doi:10.1016/j.cyto.2011.03.023

65. Feng Q, Liu D, Lu Y, Liu Z. The interplay of renin-angiotensin system and toll-like receptor 4 in the inflammation of diabetic nephropathy. Hindawi J Immunol Res. 2020;2020:1-11. doi:10. 1155/2020/6193407

66. Miao Lin M, Tang SC. Toll-like receptors: sensing and reacting to diabetic injury in the kidney. Nephrol Dial Transplant. 2014;29 (4):746-754. doi:10.1093/ndt/gft446

67. Ren Q. MON-025 toll-like receptors in glomerulonephritis. Kidney Int Rep. 2019;4(7):S1 S437. doi:10.1016/j.ekir.2019.05. 811
68. Dasu MR, Martin SJ. Toll-like receptor expression and signaling in human diabetic wounds. WJD. 2014;5(2):219-223. doi:10.42 39/wjd.v5.i2.219

69. Mohammad MK. Dysregulated toll-like receptor expression and signaling in bone marrow-derived macrophages at the onset of diabetes in the non-obese diabetic mouse. Int Immunol. 2006;18:1101-1113.

70. Creely SJ, McTernan PG, Kusminski CM, et al. Lipopolysaccharide activates an innate immune system response in human adipose tissue in obesity and type 2 diabetes. Am $J$ Physiol Endocrinol Metab. 2007;292(3):E740-E747. doi:10.11 52/ajpendo.00302.2006

71. Klein BK, Knudtson MD, Tsai MY, Klein R. The relation of markers of inflammation and endothelial dysfunction to the prevalence and progression of diabetic retinopathy: wisconsin epidemiologic study of diabetic retinopathy. Arch Ophthalmol. 2009;127(9):1175-1182. doi:10.1001/archophthalmol.2009.172

72. Tang J, Kern TS. Inflammation in diabetic retinopathy. Prog Retin Eye Res. 2011;30(5):343-358. doi:10.1016/j.preteyeres.2011.05. 002

73. Tarr JM, Kaul K, Chopra M, Kohner EM, Chibber R. Pathophysiology of diabetic retinopathy. ISRN Ophthalmol. 2013;2013:1-13. doi:10.1155/2013/343560

74. Rajamani U, Jialal I. Hyperglycemia induces toll-like receptor-2 and -4 expressions and activity in human microvascular retinal endothelial cells: implications for diabetic retinopathy. J Diabetes Res. 2014;2014:1-14. doi:10.1155/2014/790902

75. Xu WQ, Wang YS. The role of toll-like receptors in retinal ischemic diseases. Int J Opthalmol. 2016;9(9):1343-1351.

76. Rivera JC, Dabouz R, Noueihed B, Samy Omri S, Tahiri H, Sylvain S. Ischemic retinopathies: oxidative stress and inflammation. Oxid Med Cell Longev. 2017;1-16.

77. Elzinga S, Murdock BJ, Guo K, et al. Toll-like receptors and inflammation in metabolic neuropathy; a role in early versus late disease? Exp Neurol. 2019;320:1-11. doi:10.1016/j.expneurol.20 19.112967

78. Jurga AM, Rojewska E, Anna Piotrowska A, et al. Blockade of toll-like receptors (TLR2, TLR4) attenuates pain and potentiates buprenorphine analgesia in a rat neuropathic pain model. Neural Plast. 2016;2016:1-12. doi:10.1155/2016/5238730

79. Tsalamandris S, Antonopoulos AS, Oikonomou E, Papamikroulis JA, Vogiatzi G, Papaioannou S. The role of inflammation in diabetes: current concepts and future perspectives. Eur Cardiol Rev. 2019;14(1):50-59.

80. Anwar MA, Shah M, Kim J, Choi S. Recent clinical trends in tolllike receptor targeting therapeutics. Med Res Rev. 2019;39:10 53-1090.

81. Singh MV. Toll-like receptors, hypertension, and an antimalarial drug. Am J Hypertens. 2017;30(2):118-119. doi:10.1093/ajh/hpw128

82. Kapelouzou A, Giaglis S, Peroulis M, et al. Overexpression of toll-like receptors $2,3,4$, and 8 is correlated to the vascular atherosclerotic process in the hyperlipidemic rabbit model: the effect of statin treatment. J Vasc Res. 2017;54(3):156-169. doi: $10.1159 / 000457797$

83. Zimmer S, Steinmetz M, Asdonk T, et al. Activation of endothelial toll-like receptor 3 impairs endothelial function. Circ Res. 2011;108(11):1358-1366. doi:10.1161/CIRCRESAHA.111.243 246

84. Lundberg AM, Ketelhuth DF, Johansson ME, et al. Toll-like receptor 3 and 4 signalling through the TRIF and TRAM adaptors in haematopoietic cells promotes atherosclerosis. Cardiovasc Res. 2013;99(2):364-373. doi:10.1093/cvr/cvt033

85. Cole JE, Navin TJ, Cross AJ, et al. Unexpected protective role for toll-like receptor 3 in the arterial wall. Proc Natl Acad Sci U S A. 2011;108(6):2372-2377. doi:10.1073/pnas.1018515108 
86. Ishibashi M, Sayers S, D'Armiento JM, Tall AR, Welch CL. TLR3 deficiency protects against collagen degradation and medial destruction in murine atherosclerotic plaques. Atherosclerosis. 2013;229(1):52-61. doi:10.1016/j. atherosclerosis.2013.03.035

87. D'Atri LP, Etulain J, Rivadeneyra L, et al. Expression and functionality of toll-like receptor 3 in the megakaryocytic lineage $J$ Thromb Haemost. 2015;13:839-850.

88. Ellenbroek GH, Van Puijvelde GH, Anas AA, et al. Leukocyte TLR5 deficiency inhibits atherosclerosis by reduced macrophage recruitment and defective T-cell responsiveness. Sci Rep. 2017;7 (1):42688. doi:10.1038/srep42688

89. Kim J, Seo M, Kim SK, Bae YS. Flagellininduced NADPH oxidase 4 activation is involved in atherosclerosis. Sci Rep. 2016;6:25437.

90. Kim J, Yoo JY, Suh JM, et al. The flagellin-TLR5-Nox4 axis promotes the migration of smooth muscle cells in atherosclerosis. Exp Mol Med. 2019;51(7):78. doi:10.1038/s12276-019-0275-6

91. Brea D, Sobrino T, Rodriguez-Yanez M, et al. Toll-like receptors 7 and 8 expression is associated with poor outcome and greater inflammatory response in acute ischemic stroke. Clin Immunol. 2011;139(2):193-198. doi:10.1016/j.clim.2011.02.001

92. Koulis C, Chen YC, Hausding C, et al. Protective role for toll-like receptor-9 in the development of atherosclerosis in apolipoprotein E-deficient mice. Arterioscler Thromb Vasc Biol. 2014;34 (3):516-525. doi:10.1161/ATVBAHA.113.302407

93. Watkins AA, Yasuda K, Wilson GE, et al. IRF5 deficiency ameliorates lupus but promotes atherosclerosis and metabolic dysfunction in a mouse model of lupus-associated atherosclerosis. J Immunol. 2015;194(4):1467-1479. doi:10.4049/jimmunol.140 2807
94. Bouaziz JD, Calbo S, Maho-Vaillant M, et al. IL-10 produced by activated human $\mathrm{B}$ cells regulates $\mathrm{CD} 4+\mathrm{T}$-cell activation in vitro. Eur J Immunol. 2010;40(10):2686-2691. doi:10.1002/eji.201 040673

95. Wagener J, Malireddi RS, Lenardon MD, et al. Fungal chitin dampens inflammation through IL-10 induction mediated by NOD2 and TLR9 activation. PLoS Pathog. 2014;10(4): e1004050. doi:10.1371/journal.ppat.1004050

96. Lee JG, Lim EJ, Park DW, Lee SH, Kim JR, Baek SH. A combination of Lox-1 and Nox1 regulates TLR9-mediated foam cell formation. Cell Signal. 2008;20(12):2266-2275. doi:10.1016/j.cellsig.2008.08.022

97. Fukuda D, Nishimoto S, Aini K, et al. Toll-like receptor 9 plays a pivotal role in angiotensin II-induced atherosclerosis. $J \mathrm{Am}$ Heart Assoc. 2019;8(7):e010860. doi:10.1161/JAHA.118.010860

98. Sorrentino R, Morello S, Chen S, Bonavita E, Pinto A. The activation of liver $\mathrm{X}$ receptors inhibits toll-like receptor-9-induced foam cell formation. J Cell Physiol. 2009; 223:158-167.

99. Niessner A, Sato K, Chaikof EL, Colmegna I, Goronzy JJ, Weyand CM. Pathogen-sensing plasmacytoid dendritic cells stimulate cytotoxic T-cell function in the atherosclerotic plaque through interferon-alpha. Circulation. 2006;114(23):2482-2489. doi:10.1161/CIRCULATIONAHA.106.642801

100. Xu Y, Zhou Y, Lin H, Hu H, Wang Y, Xu G. Toll-like receptor 2 in promoting angiogenesis after acute ischemic injury. Int $\mathrm{J} \mathrm{Mol}$ Med. 2013;31(3):555-560. doi:10.3892/ijmm.2013.1240

101. Anders H-J. Toll-like receptors and danger signaling in kidney injury. J Am Soc Nephrol. 2010;21(8):1270-1274. doi:10.1681/ ASN.2010030233

\section{Publish your work in this journal}

Diabetes, Metabolic Syndrome and Obesity: Targets and Therapy is an international, peer-reviewed open-access journal committed to the rapid publication of the latest laboratory and clinical findings in the fields of diabetes, metabolic syndrome and obesity research. Original research, review, case reports, hypothesis formation, expert opinion and commentaries are all considered for publication. The manuscript management system is completely online and includes a very quick and fair peer-review system, which is all easy to use. Visit http://www.dovepress.com/testimonials.php to read real quotes from published authors. 